\title{
LAS EMOCIONES EN EL APRENDIZAJE ONLINE
}

\section{[Emotions in E-Learning]}

\section{$\underline{\text { Article record }}$
$\underline{\text { About authors }}$
$\underline{\text { HTML format }}$} \\ Rebollo Catalán, Ma Ángeles (rebollo@us.es) \\ García Pérez, Rafael (rafaelgarcia@us.es) \\ Barragán Sánchez, Raquel (rbarragan@us.es) \\ Buzón García, Olga (olgbuzgar@alum.us.es) \\ Vega Caro, Luisa (luiveg@us.es)
}

Ficha del artículo

$\underline{\text { Sobre los autores }}$

Formato HTML

\begin{abstract}
This paper presents the results of an educational innovation in Higher Education, whose aim is to design and test a pedagogical model for e-learning. This paper has the main aim to identify and evaluate emotional factors related to elearning by means of a survey research. The results show emotional well-being scores higher than wrong-being, identifying a range of emotions, which are related to different emotional states in e-learning. In addition, we present features of teachers' and students' virtual discourses in forums of discussion starting from types of educational interaction and kind of emotions related to certain settings of learning activity.
\end{abstract}

\section{Keywords}

E-learning; higher education; emotions; emotional regulation; pedagogy of emotions.

\section{Resumen}

Este artículo presenta parte de los resultados de una innovación educativa en el nivel universitario, cuyo propósito es elaborar y experimentar un modelo pedagógico para el aprendizaje online. Con este estudio pretendemos reconocer y valorar las emociones implicadas en el aprendizaje online mediante un método descriptivo de tipo encuesta. Los resultados indican mayor nivel de bienestar emocional que de malestar, identificándose las emociones asociadas a estos estados emocionales presentes en el aprendizaje online. También presentamos las características de los discursos virtuales del profesorado y del alumnado en función de tipos de interacción y emociones asociadas a determinados contextos de actividad.

\section{Descriptores}

Aprendizaje online; educación superior; emociones; regulación emocional; pedagogía de las emociones.

\section{INTRODUCCIÓN}

Este artículo presenta los resultados de una innovación educativa en el nivel universitario basada en la aplicación de un modelo pedagógico semi-presencial con el desarrollo de un entorno virtual en Moodle para el aprendizaje universitario.

La adaptación de las titulaciones universitarias al nuevo sistema de Créditos Europeos requiere la elaboración de recursos para el aprendizaje, con especial atención en la aplicación y aprovechamiento de las Tecnologías de la Información y la Comunicación para promover un aprendizaje autónomo. Diversas iniciativas institucionales puestas en marcha por las Universidades Europeas van encaminadas a la renovación de metodologías docentes y de forma especial a desarrollar modelos instruccionales online mediante plataformas formativas virtuales (Ardizzone 
y Rivoltella, 2004; Garrison y Anderson, 2005; Bautista et al., 2006; Rué, 2007; Aliaga y Bartolomé, 2006). La incorporación de las TIC como recursos para el aprendizaje universitario supone uno de los retos actuales para la renovación de metodologías y estrategias didácticas.

Por su parte otras investigaciones científicas documentan una tasa de abandono importante en los sistemas de teleformación y e-learning, fenómeno en el que parece tener un importante papel la motivación y la emoción del alumnado así como las características de los entornos virtuales para la formación. En este trabajo tratamos de conocer las emociones que se ponen en juego en el aprendizaje online así como los estados emocionales que estos procesos generan. Con este objetivo, hemos adoptado una concepción constructivista de las emociones que nos permite explorar y profundizar en las relaciones entre emoción y contexto, siendo una teoría especialmente útil para abordar el estudio de emociones morales presentes en los procesos de aprendizaje (vergüenza, culpabilidad, orgullo, etc.). Esta perspectiva permite sondear vías para comprender las relaciones entre emociones, aprendizaje y valores sociales presentes en los recursos, contenidos y entornos educativos.

\section{LA INVESTIGACIÓN EDUCATI- VA SOBRE EMOCIONES}

En un análisis reciente del estado de la investigación educativa sobre las emociones, Pekrun (2005) señala la escasa atención que han recibido las emociones en los procesos educativos durante el siglo XX con dos notables excepciones: el estudio de la ansiedad relacionada con la evaluación y el rendimiento (exámenes, tests, etc.) y el estudio de la relación entre emoción y motivación relacionada con el éxito y fracaso académico (culpa, orgullo, etc.). En su análisis, Pekrun reconoce el escaso conocimiento del que disponemos aún sobre la ocurrencia, frecuencia y fenomenología de las emociones en diferentes entornos de aprendizaje y, muy especialmente, en el aprendizaje online.

El estudio científico de las emociones desde una perspectiva educativa ha estado marcado por la miopía de la ciencia del siglo XX a tratar las emociones como objeto de estudio. Las concepciones racionalistas y empiristas dominantes en la ciencia moderna han derivado en una invisibilidad social y científica de las emociones y, como consecuencia en una invisibilidad de metodologías científicas y de modelos pedagógicos aplicados. En la última década, la irrupción de nuevas concepciones científicas abre el camino para la investigación científico-educativa en este campo. Teorías sociales como el feminismo y el postmodernismo han supuesto referentes teóricos novedosos, que incorporan nuevas concepciones respecto a la persona y al acto educativo con importantes derivaciones científicas en educación. Estas teorías han venido a sustentar una concepción de la persona como ser histórico, construido socialmente en interacción con los contextos sociales, lo que ha abierto la puerta al estudio e incorporación de las emociones en los procesos educativos.

La relación emocional con nuevas herramientas y contenidos de aprendizaje supone una línea de estudio, especialmente interesante en relación con el e-learning y la teleformación (Ekflides, 2006; Etchevers, 2005; Aires et al., 2006; Rebollo et. al, 2008). El estudio de las resistencias, actitudes y emociones en relación con el uso de las tecnologías como recurso de aprendizaje se muestra particularmente necesario para reducir los índices de abandono y fracaso que presentan los modelos de e-learning. Especialmente ahora que, cada vez más, la calidad de la educación se evalúa y mide a través de una gama de indicadores entre los cuales se contempla la tasa de abandono prematuro de los estudios. En una revisión de estudios, Cabrera et al. (2006) sintetizan algunos factores asociados al abandono prematuro de estudios: baja autoestima, incapacidad para de- 
morar recompensas o superar obstáculos, escasa integración académica y social. Otras investigaciones y estudios recientes sobre fracaso escolar desde una perspectiva internacional sondean en las lógicas de inclusión y exclusión que caracteriza la cultura escolar y entre otros factores asociados señalan cuestiones relacionadas con la cultura de género y la regulación de las emociones. (Marchesi y Hernández, 2003; Rebollo, Hornillo y García, 2006).

Un número creciente de investigaciones educativas se centran en el diseño y experimentación de entornos de aprendizaje online que incorporan recursos, estrategias y actividades de regulación emocional (Barragán et al., 2007; Aires et al., 2006; Etchevers, 2005; Bostock y Lizhi, 2005). Estos trabajos analizan la comunicación emocional en el aprendizaje online.

Efklides (2006) estudia la relación entre metacognición y afecto a través de lo que denomina experiencias metacognitivas. Estas comprenden sentimientos, juicios o valoraciones y conocimientos específicos sobre la tarea online. Entre otros aspectos, se centra en los sentimientos de dificultad, familiaridad y confianza, estrechamente relacionados con la metacognición: estimación del tiempo y el esfuerzo que requiere la tarea, tipo de conocimiento y respuesta que requiere, expectativas de éxito, etc. Este estudio parece de especial relevancia para el diseño de entornos de aprendizaje en el nivel universitario en un momento en el que la adaptación de las titulaciones universitarias al nuevo sistema de Créditos Europeos requiere la elaboración de recursos para el aprendizaje de los alumnos, con especial atención en la aplicación y aprovechamiento de las TICs para promover un aprendizaje autónomo. Las actuales concepciones de aprendizaje adulto y aprendizaje a lo largo de la vida, que sustentan el informe y propuestas del Consejo de Lisboa para la educación, incluyen competencias comunicativas, metacognitivas $\mathrm{y}$ afectivas y formas de pensamiento reflexivo, evaluativo y contextual como facetas clave en la formación, siendo necesario identificar y caracterizar modelos pedagógicos para el e-learning que integren estas facetas.

Aires et al. (2006) presentan un análisis reticular de las interacciones emocionales en comunidades virtuales de aprendizaje de gran valor y utilidad para derivar orientaciones y recomendaciones para la práctica educativa online (andamiaje emocional online, teletutorías, etc.). En esta misma vertiente, Barragán et al. (2007) han experimentado estrategias y mecanismos de interacción y regulación online aplicados en dos prototipos de actividades: enseñanza recíproca de resolución de tareas (díadas) y aprendizaje online basado en proyectos (trabajo en grupo), identificando la regulación afectiva entre las principales formas de regulación online asociadas a la satisfacción del alumnado. La identificación de una variedad de estrategias discursivas, utilizadas tanto por el profesorado como por el alumnado durante las interacciones educativas online, aporta claves para el diseño y desarrollo de fórmulas comunicativas para la regulación emocional en las interacciones educativas.

Resulta especialmente sugerente la contribución de Nicole Etchevers (2006) para el análisis del discurso emocional en la comunicación online. Con el término "Lenguaje Complementado", esta autora formula un concepto útil que incluye un catálogo de códigos y reglas de escritura que sirven para reforzar o "complementar" la comunicación educativa virtual. Entre estos códigos, que los usuarios usamos, señala: emoticones (J), onomatopeyas (jajaja, mua, m-mhmm), acrónimos, repetición de vocablos (excelenteeee$e e$ ), intensificación y repetición de signos de puntuación (gracias!!!!), el uso de mayúsculas (POR FAVOR), etc.

Por su parte, Bostock y Lizhi (2005) analizan y comparan la calidad y tipo de discursos en las discusiones online en función del género y las características del grupo. Se reali- 
za un experimento formativo, dividiendo a los alumnos para la discusión en tres grupos de diferente composición: hombres, mujeres y mixtos. Se observan diferencias importantes en la discusión online entre el grupo de hombres y mujeres, siendo más numerosos los mensajes en el de las mujeres. La preferencia por la comunicación online así como expectativas más altas en relación con el aprendizaje parece guiar esta tendencia. Los datos obtenidos de la interacción online en grupos mixtos revelan que mientras los chicos mejoran su capacidad comunicativa, las chicas inhiben sus intervenciones. Resulta especialmente interesante el análisis de contenido de los mensajes de foros de discusión, en el que los autores contemplan cinco dimensiones: participativos, sociales, interactivos, cognitivos y metacognitivos.

En definitiva, los resultados de investigaciones recientes sobre emociones y aprendizaje online aconsejan la incorporación del afecto y la emoción en el diseño y desarrollo de entornos de aprendizaje online. En este trabajo presentamos los datos de un modelo didáctico semi-presencial (blendedlearning), en cuyo diseño y evaluación se han contemplado estas facetas emocionales. Concretamente, mostramos las emociones experimentadas durante el aprendizaje online por parte de una comunidad de estudiantes universitarios.

\section{CONCEPCIÓN HISTORICO- CULTURAL DE LAS EMOCIONES}

En este estudio adoptamos una visión dialógica de base sociogenética de las emociones según la cual éstas son actuaciones culturales aprendidas y realizadas en las ocasiones oportunas. Según esta concepción, los procesos educativos se conciben, en última instancia, como procesos de andamiaje emocional. Una línea de trabajos aborda específicamente las emociones desde un enfoque sociocultural (Gover, 1996; Gover y Gavelek, 1997; Edwards, 1999; Hong, 2004; Rebollo 2006).
Esta perspectiva científica de las emociones se sustenta en las siguientes consideraciones:

1) Cuando hablamos de sentimientos no nos referimos a un proceso exclusivamente individual e interno, sino a un proceso relacional. La emoción se construye socialmente.

2) Las emociones están mediadas por instrumentos y recursos culturales de naturaleza simbólica que nos proveen los contextos sociales. Estos instrumentos son clave para construir nuestra identidad (autoestima, estilo afectivo, etc.).

3) Los sentimientos tienen un horizonte moral, es decir, suponen indicadores de la relación que establecemos con los contextos en tanto que éstos encarnan unos determinados valores culturales y actuamos en relación con ellos privilegiándolos o rechazándolos.

Algunas nociones teóricas resultan de interés para el estudio sociocultural de las emociones: mediación y agencialidad. Ambas proponen un marco explicativo para la comprensión de las relaciones dialógicas entre emoción y contexto.

La mediación cultural es un concepto propuesto por Vygotski y ampliamente tratado en las investigaciones socioculturales (Wertsch, 1993; De Pablos et al., 1999). En relación con la educación emocional, las situaciones prototípicas de aprendizaje emocional proponen unas formas de sentir y actuar a las personas que participan en ellas a través de un repertorio de herramientas mediadoras. Estos mediadores encarnan ideales culturales y valores sociales y a través de ellos se transmiten creencias $y$ formas de acción generadas socialmente.

Agencialidad, por su parte, es una noción introducida por Wertsch (1999) a partir de las contribuciones y escritos de Bajtin. La agencialidad se define como un tipo de acción responsable llevada a cabo por una persona para desarrollar sus objetivos usando los modos de mediación propios de cada 
escenario sociocultural. El uso de mediadores permite ganar o perder autoridad, en otras palabras, son recursos de empoderamiento personal. Estas formas de usar los mediadores nos informan de la representación subjetiva que una persona se hace de la situación, al elegir un tipo de mediador y usarlo de un modo muy determinado (bien para regular a otros, bien para autorregularse). Las emociones, en última instancia, son modos de actuar y de relacionarse con el sistema de valores que encarnan los contextos y los mediadores culturales que los caracterizan. Como el propio Wertsch (1999) ha comentado, la introducción de un nuevo mediador en un escenario cambia la estructura de poder. El hecho de que la educación incorpore las tecnologías como medio de aprendizaje, introduce cambios en la organización, política y cultura escolar, dando un mayor protagonismo a ciertas habilidades antes no contempladas y ciertas formas de aprendizaje autónomo y autorregulado (planificación, sistematización, constancia y disciplina).

En este plano, un trabajo realizado por Hargreaves (2003) resulta sugerente para el análisis y comprensión de las relaciones entre emoción y poder en los procesos educativos. En él, Hargreaves propone que las emociones de las personas se forman en parte por las experiencias de poder y de impotencia. Su análisis se centra en explicar las lógicas de éxito y fracaso en educación a partir de la capacidad de las personas para intervenir directamente en la realización de sus proyectos y planes de vida, permitiendo la comprensión de las emociones que están asociadas al poder. Basándonos en este trabajo y en las aportaciones socioculturales sobre agencialidad antes expuestas, hemos elaborado un gráfico que nos permite representar algunas emociones en función de dos ejes: responsabilidad y poder.

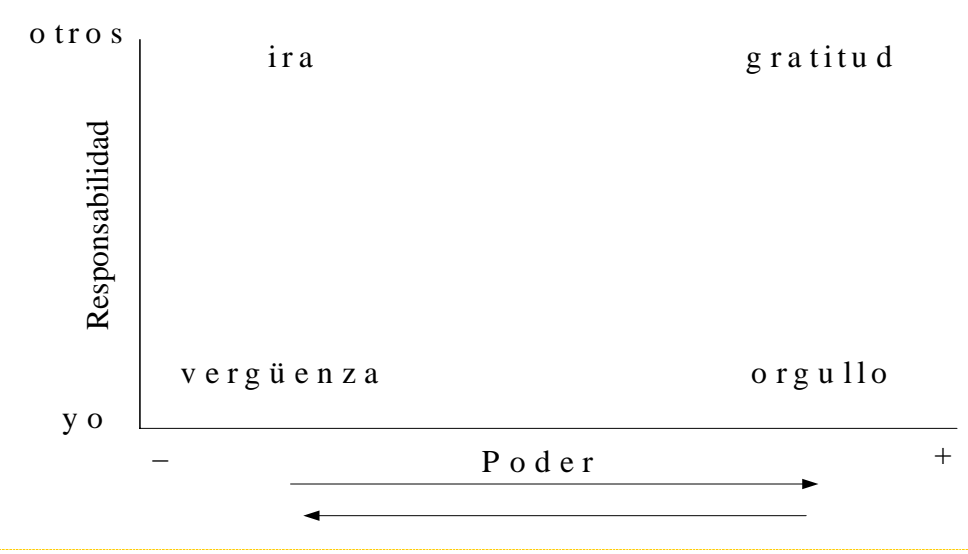

Gráfico 1. Emociones en función del poder y la responsabilidad

Según este modelo, existen una serie de emociones relacionadas con los procesos de empoderamiento, estando asociados los sentimientos de orgullo y gratitud a un aumento de nuestro poder personal, mientras que vergüenza e ira se asocian a la pérdida de poder. De este modo, cuando experimentamos un aumento de nuestro propio poder sentimos orgullo si somos responsables de esa ganan- cia y gratitud si el responsable es otra persona. Otros sentimientos que se asocian a este empoderamiento son seguridad y satisfacción. Por el contrario, cuando se reduce nuestro poder, sentimos rabia hacia los responsables si son otras personas o vergüenza si nos creemos los propios responsables, apareciendo también asociados el miedo y la ansiedad. 
Este modelo explicativo de las emociones en los procesos educativos otorga un papel central al poder como valor social y como símbolo de la capacidad individual, a partir del cual podemos descubrir un abanico de emociones que se ponen en juego en las interacciones educativas y en las relaciones interpersonales en contextos formales.

\section{OBJETIVOS}

El presente trabajo tiene como propósito general conocer y valorar las emociones implicadas en el aprendizaje universitario online, siendo objetivos más específicos:

- Identificar el nivel de bienestar y malestar emocional experimentado por los estudiantes universitarios en el aprendizaje online.

- Detectar la variedad de emociones positivas y negativas experimentadas en relación con el aprendizaje online y el grado en que están presentes.

- Descubrir patrones de asociación entre distintos tipos de emociones experimentadas por el alumnado en el aprendizaje online.

- Conocer y caracterizar los tipos de discursos virtuales de alumnado y profesorado en función del tipo de interacción educativa y emociones que manifiestan.

\section{MÉTODO}

Esta investigación de carácter evaluativo adopta un diseño descriptivo de tipo encuesta o survey, haciendo uso de técnicas cuantitativas y cualitativas para el conocimiento y valoración de las emociones experimentadas durante el aprendizaje online. Este tipo de diseño suelen aplicarse a la evaluación de innovaciones educativas con el objeto de detectar factores que condicionan su aplicación y describir y conocer cómo funcionan en la práctica. En este estudio, el diseño elegido nos permite conocer y valorar las emociones experimentadas durante la realización de las actividades y tareas de aprendizaje online.

\subsection{Participantes}

El estudio se realiza en dos grupos de estudiantes universitarios del primer curso de la titulación de Pedagogía. El número total de alumnado matriculado es de 196. La muestra invitada está compuesta por 113 estudiantes que han participado de forma regular y han realizado el plan propuesto de actividades, de los cuales un $46,9 \%$ proceden de bachillerato, un $42,47 \%$ repiten la asignatura y un $10,61 \%$ la cursan como complemento de formación. Los participantes que componen la muestra real del estudio han sido 59, de los cuales un $47,4 . \%$ son repetidores, un $44,06 \%$ proceden de bachillerato y $8,4 \%$ la han cursado como complemento de formación. Esto nos indica que, aunque la muestra real es menor que la invitada, las distribuciones de ambas son muy similares en cuanto a la representación porcentual de cada perfil de participantes. 
Rebollo Catalán, Mª A., García Pérez, R., Barragán Sánchez, R., Buzón García, O. y Vega Caro, L. (2008). Las emociones en el aprendizaje online. RELIEVE, v. 14, n. 1, p. 1-23.

http://www.uv.es/RELIEVE/v14n1/RELIEVEv14n1_2.htm

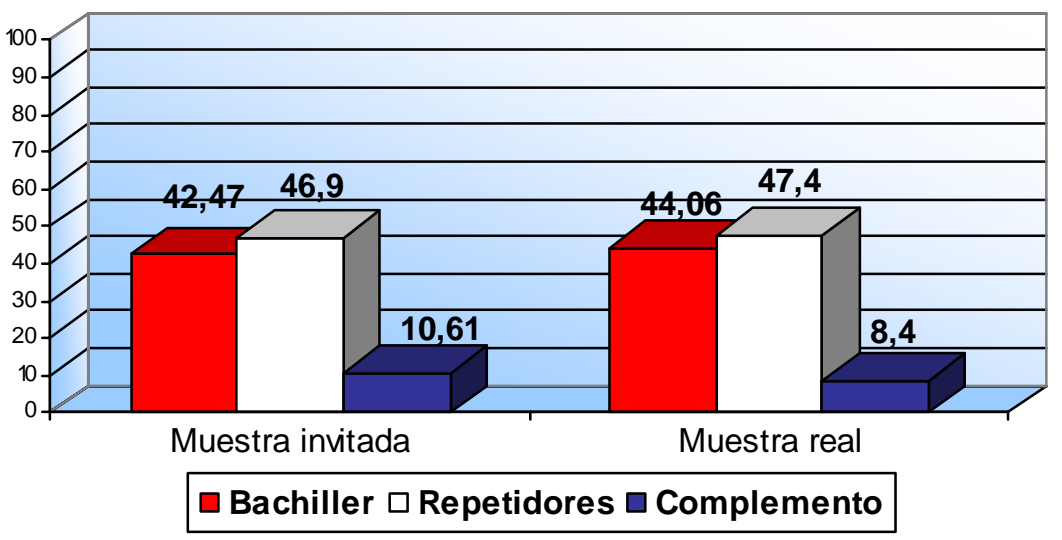

Gráfico 2. Distribución porcentual de la muestra invitada y real según perfiles participantes

El alumnado participante son en su mayoría mujeres, representando el $83,05 \%$ de la muestra, siendo el 16,94\% hombres. Esta es la proporción característica de hombres y mujeres en los estudios de Pedagogía. En cuanto a la edad de los participantes, los datos indican una media de 20,21 años, con una moda de 19 y una desviación típica de 2,00; donde la edad mínima es de 18 años, que se refiere al alumnado de primer ingreso y con un máximo de 27, que normalmente corresponde a repetidores o personas que cursan la materia como complemento de formación desde otras titulaciones.

\subsection{Procedimiento}

El procedimiento ha consistido en un "experimento formativo" desarrollado en fases sucesivas. La siguiente ilustración muestra las características de este experimento formativo, incluyéndose características de la innovación educativa junto con estrategias puramente científicas de obtención y tratamiento de la información.

\begin{tabular}{|c|c|c|c|c|c|}
\hline & Unidad A & Unidad B & Unidad C & \multicolumn{2}{|c|}{ Global } \\
\hline Contenido & Paradigmas & $\begin{array}{l}\text { Metodología } \\
\text { Experimental }\end{array}$ & $\begin{array}{c}\text { Metodología } \\
\text { Cualitativa }\end{array}$ & & \\
\hline $\begin{array}{c}\text { Tarea de } \\
\text { Aprendizaje }\end{array}$ & $\begin{array}{l}\text { Plantea una pro- } \\
\text { blemática educa- } \\
\text { tiva desde dos o } \\
\text { más paradigmas }\end{array}$ & $\begin{array}{l}\text { Idea y diseña un } \\
\text { experimento edu- } \\
\text { cativo }\end{array}$ & $\begin{array}{c}\text { Elabora un } \\
\text { ejemplo de in- } \\
\text { vestigación cua- } \\
\text { litativa }\end{array}$ & & \\
\hline Método & $\begin{array}{c}\text { Estudio de Casos } \\
\text { Flexibilidad Cog- } \\
\text { nitiva }\end{array}$ & $\begin{array}{l}\text { Aprendizaje basa- } \\
\text { do en proyectos }\end{array}$ & $\begin{array}{l}\text { Aprendizaje } \\
\text { basado en } \\
\text { proyectos }\end{array}$ & & \\
\hline Temporalización & $\begin{array}{l}\text { Mensual } \\
\text { Marzo }\end{array}$ & $\begin{array}{c}\text { Mensual } \\
\text { Abril }\end{array}$ & $\begin{array}{l}\text { Mensual } \\
\text { Mayo }\end{array}$ & & \\
\hline $\begin{array}{l}\text { Diseño } \\
\text { Metodolórico }\end{array}$ & $\begin{array}{c}\text { Foro de discusión } \\
\text { A }\end{array}$ & $\begin{array}{c}\text { Foro de Discusión } \\
\text { B }\end{array}$ & $\begin{array}{l}\text { Foro de Discu- } \\
\text { sión C }\end{array}$ & $\begin{array}{l}\text { Cuestionario } \\
\text { de valoración } \\
\text { emocional }\end{array}$ & $\begin{array}{c}\text { Entrevista } \\
\text { grupal }\end{array}$ \\
\hline & & Análisis del discurso & & $\begin{array}{c}\text { Análisis } \\
\text { estadístico }\end{array}$ & $\begin{array}{l}\text { Análisis } \\
\text { contenido }\end{array}$ \\
\hline
\end{tabular}

Tabla 1. Procedimiento y estrategias metodológicas del estudio. 
Rebollo Catalán, Ma . A., García Pérez, R., Barragán Sánchez, R., Buzón García, O. y Vega Caro, L. (2008). Las emociones en el aprendizaje online. RELIEVE, v. 14, n. 1, p. 1-23.

http://www.uv.es/RELIEVE/v14n1/RELIEVEv14n1_2.htm

El estudio se centra en la evaluación del proceso mediante dos estrategias. La primera consiste en el registro de las emociones experimentadas por los estudiantes mediante los discursos virtuales desarrollados en los foros de discusión. La segunda consiste en una estrategia de valoración global de la experiencia de aprendizaje online mediante dos procedimientos; una entrevista grupal al alumnado y la aplicación de un cuestionario de valoración de las emociones puestas en juego en su conjunto y cumplimentado por el alumnado al final del curso. En éste último, se solicita expresamente que manifiesten las emociones que han experimentado durante las actividades de aprendizaje online, valo- rando los sentimientos presentes al usar el entorno virtual del curso.

\subsection{Material}

El material proporcionado al alumnado para el aprendizaje online de la asignatura se desarrolla bajo el entorno virtual de la plataforma Moodle, aplicando un modelo de curso semi-presencial (blended-learning). La disponibilidad y calidad de recursos para la comunicación y la construcción colaborativa de conocimientos (wiki, foro, chat, taller, etc.), que ofrece esta plataforma la hacen especialmente adecuada para este proyecto. El siguiente gráfico muestra la interfaz del curso en Internet:

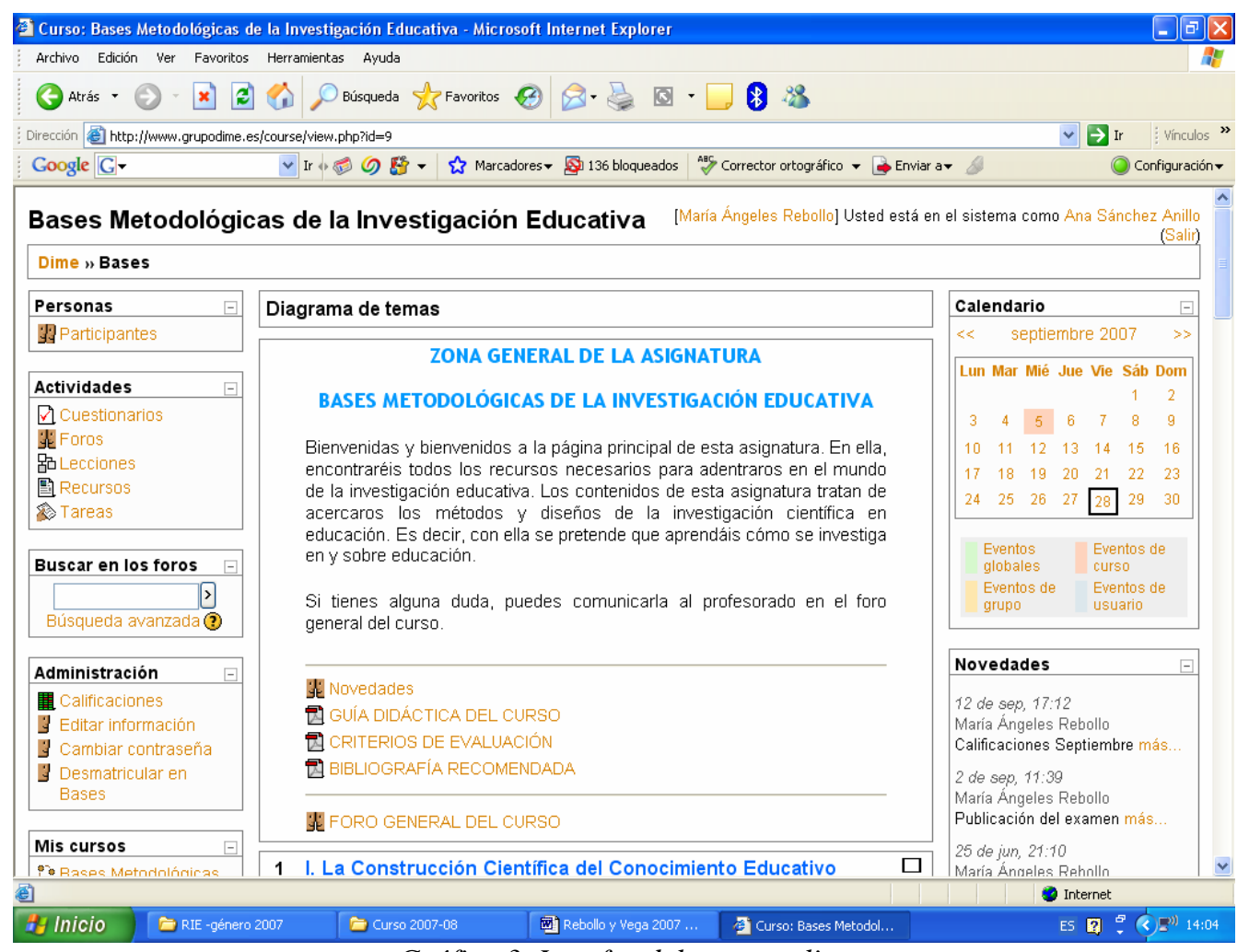

Gráfico 3. Interfaz del curso online

Cada unidad de aprendizaje contiene tres tipos de recursos: recursos orientados al aprendizaje cognitivo (teoría), recursos orientados al aprendizaje práctico (práctica) y, recursos orientados a la comunicación y al aprendizaje colaborativo. La tabla siguiente muestra la variedad de recursos tecnológicos disponibles para el aprendizaje online. 
Rebollo Catalán, Ma. A., García Pérez, R., Barragán Sánchez, R., Buzón García, O. y Vega Caro, L. (2008). Las emociones en el aprendizaje online. RELIEVE, v. 14, n. 1, p. 1-23.

http://www.uv.es/RELIEVE/v14n1/RELIEVEv14n1_2.htm

\begin{tabular}{|c|c|c|}
\hline Orientación & Recurso & Descripción \\
\hline \multirow{3}{*}{ Teoría } & Lección & $\begin{array}{l}\text { Cada tema tiene una estructura jerárquica ramificada e hipertextual, } \\
\text { incorporando organizadores, ejemplos y un glosario. }\end{array}$ \\
\hline & Autoevaluación & $\begin{array}{l}\text { Pruebas objetivas de opción múltiple que sirven de chequeo rápido de } \\
\text { conocimientos básicos de cada unidad. Son pruebas de velocidad. }\end{array}$ \\
\hline & Bibliografía & $\begin{array}{l}\text { Esta sección ofrece referencias a bibliografía (monografías, revistas, } \\
\text { etc.) y otros recursos para documentarse (bases de datos, centros de } \\
\text { documentación, etc.) }\end{array}$ \\
\hline \multirow{3}{*}{ Práctica } & Tarea & $\begin{array}{l}\text { Son ejercicios, tareas y prácticas de aprendizaje que se proponen a los } \\
\text { estudiantes y que se pueden realizar virtualmente. }\end{array}$ \\
\hline & Guía & $\begin{array}{l}\text { Se trata de un documento explicativo del sentido, pasos y características } \\
\text { de la tarea. Es una guía práctica o manual de ayuda para la realización } \\
\text { de las actividades y prácticas de aprendizaje. }\end{array}$ \\
\hline & Ejemplo & $\begin{array}{l}\text { Consiste en un ejemplo didáctico o resolución simulada de una tarea. } \\
\text { Adopta la forma de un modelo o prototipo de buena práctica. }\end{array}$ \\
\hline \multirow{2}{*}{$\begin{array}{l}\text { Comunica- } \\
\text { ción }\end{array}$} & Foro & $\begin{array}{l}\text { Se propone a modo de taller virtual con demostraciones virtuales de } \\
\text { errores típicos, buenas prácticas, etc. Suponen tutorías virtuales colecti- } \\
\text { vas. }\end{array}$ \\
\hline & Correo & $\begin{array}{l}\text { Su uso es muy restringido a consultas de carácter privado y referida a } \\
\text { procesos personales. }\end{array}$ \\
\hline
\end{tabular}

Tabla 2. Catálogo de recursos tecnológicos para el aprendizaje online.

\subsection{Instrumentos}

La instrumentación empleada en este estudio consiste en un cuestionario, foros de discusión y entrevista grupal.

Se diseña y aplica un cuestionario sobre emociones en el aprendizaje online compuesto por 40 ítems tipo likert, que se desglosan en 20 referidos a emociones positivas y 20 sobre emociones negativas y cuya respuesta oscila entre $0=$ nunca, $1=$ ocasionalmente, $2=$ en bastantes ocasiones y $3=$ todo el tiempo.
A partir de los ítems del cuestionario se conforman dos medidas indicadoras de las emociones: Bienestar Emocional y Malestar Emocional, obteniendo un coeficiente Alfa de Cronbach de 0.919 para la escala de bienestar emocional y 0.932 para la escala de malestar emocional y presentando índices de fiabilidad óptimos. La tabla siguiente muestra los resultados obtenidos del escalamiento óptimo (CATPCA -ordinal-) y los coeficientes.

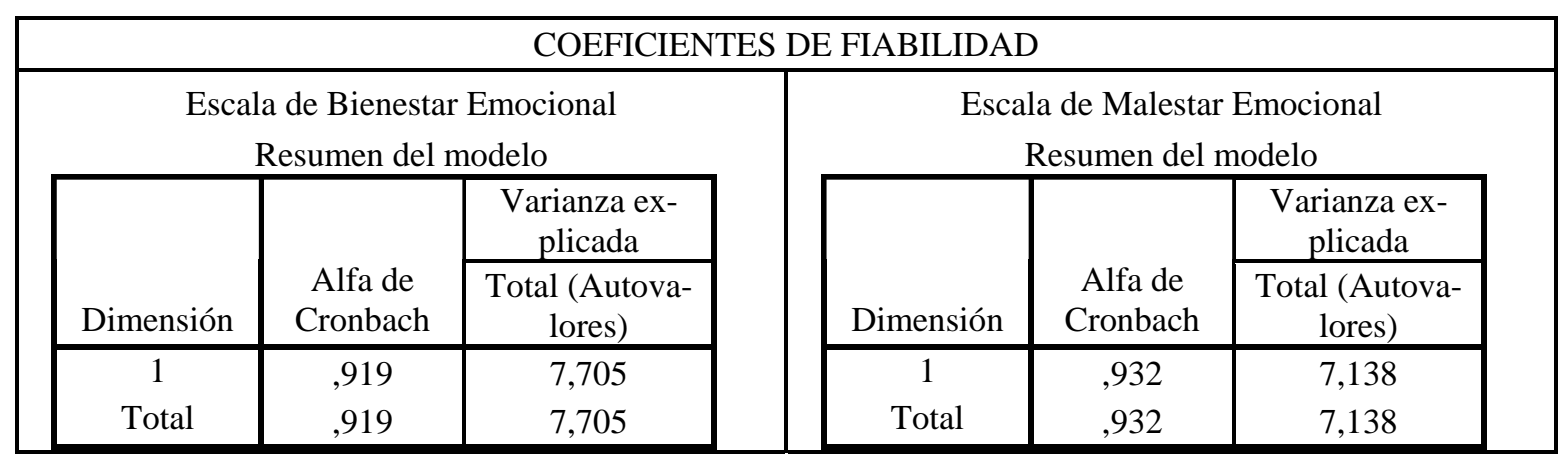

Tabla 3. Coeficientes de fiabilidad de la escala de emociones positivas y de emociones negativas. 
Rebollo Catalán, Ma . A., García Pérez, R., Barragán Sánchez, R., Buzón García, O. y Vega Caro, L. (2008). Las emociones en el aprendizaje online. RELIEVE, v. 14, n. 1, p. 1-23.

http://www.uv.es/RELIEVE/v14n1/RELIEVEv14n1_2.htm

Las escalas de valoración de bienestar y malestar emocional muestran, cada una, unidimensionalidad presentando índices altos de saturación en el componente principal de todas las emociones, a excepción de euforia en la escala de emociones positivas (bienestar emocional). En la escala de las emociones negativas (malestar emocional), se observan índices altos de saturación en el componente principal de 13 emociones, quedando excluidas culpabilidad, tristeza, inseguridad, arrepentimiento, soledad, desconfianza y vergüenza.

\begin{tabular}{|c|c|c|c|}
\hline \multicolumn{4}{|c|}{$\begin{array}{l}\text { VALIDEZ DE CONSTRUCTO } \\
\end{array}$} \\
\hline \multicolumn{2}{|c|}{ Escala de Bienestar Emocional } & \multicolumn{2}{|c|}{ Escala de Malestar Emocional } \\
\hline \multicolumn{2}{|c|}{ Saturaciones en componentes } & \multicolumn{2}{|c|}{ Saturaciones en componentes } \\
\hline & $\begin{array}{c}\text { Dimensión } \\
1\end{array}$ & & $\begin{array}{c}\text { Dimensión } \\
1\end{array}$ \\
\hline satisfacción & ,623 & aburrimiento &, 597 \\
\hline entusiasmo & ,739 & frustración & 617 \\
\hline orgullo & ,490 & enfado & ,485 \\
\hline optimismo & ,709 & fastidio & ,835 \\
\hline competencia & ,758 & angustia & ,833 \\
\hline alegría & 694 & desesperación & 995 \\
\hline alivio & ,594 & estrés & ,744 \\
\hline serenidad & ,650 & apatía & 848 \\
\hline seguridad & ,508 & asco & 483 \\
\hline tranquilidad & ,771 & desorientación & 920 \\
\hline perseverancia & ,707 & rabia & 663 \\
\hline acompañamiento & ,589 & impotencia & 629 \\
\hline confianza & 625 & tensión & ,772 \\
\hline orientación & ,454 & & \\
\hline atracción & ,542 & & \\
\hline reconocimiento & 692 & & \\
\hline agradecimiento & ,707 & & \\
\hline poder &, 530 & & \\
\hline estímulo & ,589 & & \\
\hline
\end{tabular}

Tabla 4. Validez de constructo de la escala de bienestar y malestar emocional

Ambas escalas producen medidas de bienestar y malestar emocional, que se hacen comparables mediante el cálculo de un índice del estado emocional que se expresa en valores entre 0 y 1.

Con un carácter más valorativo y abierto se han tomado datos procedentes de foros de discusión y entrevistas. Ambos procedimientos nos permite recabar opiniones, percepciones y valoraciones sobre la experiencia de aprendizaje online con objeto de valorar los cambios y beneficios de esta experiencia en un plano emocional. Los foros de discusión online registran discursos, opiniones y valoraciones que ilustran las emociones expresadas durante el proceso de aprendizaje. Se analizan 478 mensajes producidos en el proceso de aprendizaje.

De forma complementaria, se ha realizado una entrevista grupal semiestructurada a una muestra de 8 participantes en la experiencia atendiendo a criterios teóricos de máxima diversidad, (género, rol, tipo de participación, etc.), para recabar opiniones, percepciones y valoraciones sobre puntos fuertes $\mathrm{y}$ débiles de la experiencia formativa. La en- 
Rebollo Catalán, Ma . A., García Pérez, R., Barragán Sánchez, R., Buzón García, O. y Vega Caro, L. (2008). Las emociones en el aprendizaje online. RELIEVE, v. 14, n. 1, p. 1-23.

http://www.uv.es/RELIEVE/v14n1/RELIEVEv14n1_2.htm

trevista se realiza a la finalización de la experiencia y antes de la publicación de calificaciones para reducir fuentes de influencia externa en las opiniones del alumnado, asimismo la entrevista es realizada y conducida por personal ajeno al diseño y desarrollo de la materia (quedando excluido el profesorado encargado de la misma).

\section{RESULTADOS}

Los datos obtenidos mediante las escalas de evaluación se han analizado mediante el paquete estadístico SPSS y se han aplicado técnicas descriptivas y de correlación. Los datos procedentes de foros de discusión y entrevistas se han tratado con técnicas cualitativas de reducción, organización y exposi- ción de datos disponibles en ATLAS/ti y con técnicas estadísticas para datos categóricos utilizando el programa SPAD-n.

\subsection{Emociones en el aprendizaje online}

El estudio descriptivo, de los índices (0-1) de bienestar y malestar emocional en el aprendizaje online, revela que el bienestar emocional obtiene un índice medio más alto (media $=0,43$; con una desviación típica de 0,17 y una moda de 0,49 ) que el malestar que alcanza una media de 0,23 (con una desviación típica de 0,17 y una moda de 0,05 ). Esto indica que el nivel de bienestar emocional experimentado por los participantes a lo largo del proceso es muy superior a la media obtenida en el índice de malestar.

\begin{tabular}{|c|c|c|c|}
\hline \multicolumn{2}{|l|}{ Bienestar } & \multicolumn{2}{|l|}{ Malestar } \\
\hline Válidos & 55 & Válidos & 54 \\
\hline Media & ,4274 & Media & ,2317 \\
\hline Mediana & ,4561 & Mediana & 2179 \\
\hline Moda & ,49 & Moda & ,05 \\
\hline Desv. típ. & 17457, & Desv. típ. & 17355, \\
\hline Mínimo & ,05 & Mínimo & ,00 \\
\hline Máximo & ,96 & Máximo & ,74 \\
\hline Suma & 23,51 & Suma & 12,51 \\
\hline
\end{tabular}

Tabla 5. Resultados descriptivos del bienestar y malestar emocional

La siguiente ilustración muestra, en primer plano, el alto índice de bienestar emocional experimentado por los participantes frente al índice de malestar emocional que acumulan, representado en un segundo plano. Esto indi- ca un grado aceptable de bienestar emocional frente a malestar, siendo especialmente significativo si se tiene en cuenta el perfil de los participantes (casi el 50\% repetidores). 
Rebollo Catalán, Ma . A., García Pérez, R., Barragán Sánchez, R., Buzón García, O. y Vega Caro, L. (2008). Las emociones en el aprendizaje online. RELIEVE, v. 14, n. 1, p. 1-23.

http://www.uv.es/RELIEVE/v14n1/RELIEVEv14n1_2.htm

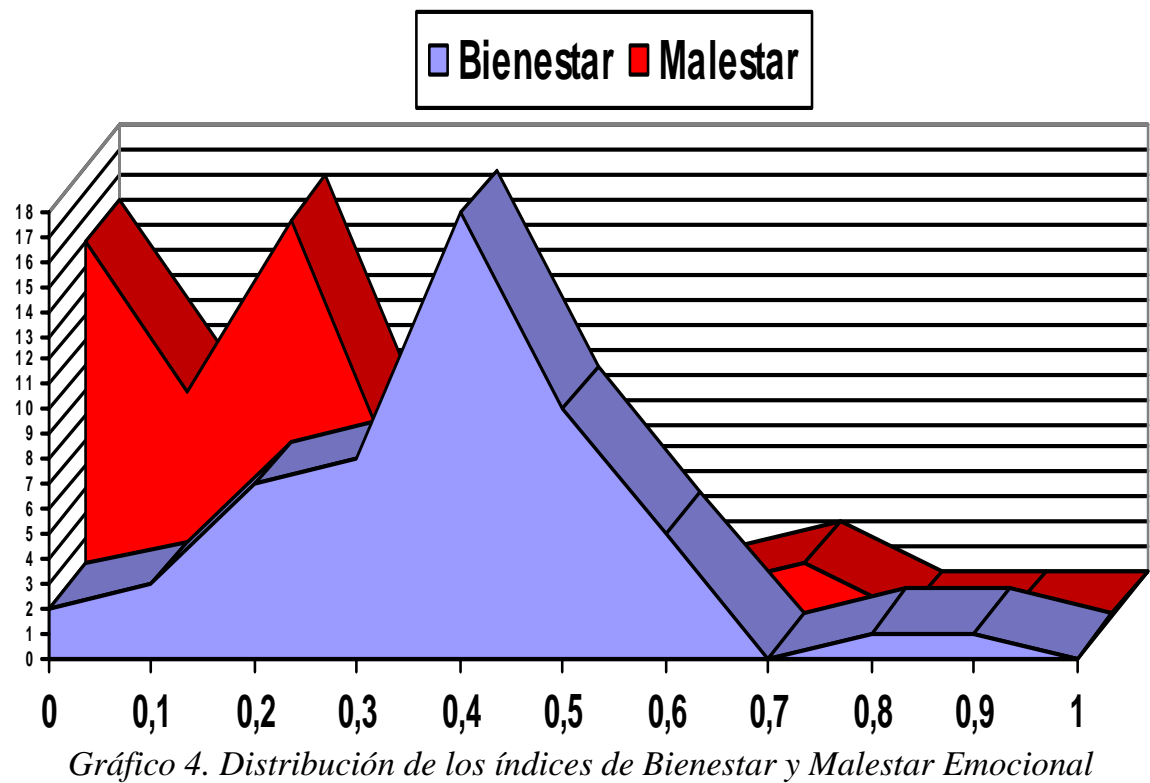

En un análisis pormenorizado de la presencia de cada emoción durante el aprendizaje online, los resultados obtenidos en el cuestionario muestran valores más altos en emociones positivas con una media de 1,3 que en emociones negativas cuya media es de 0,7 , oscilando el rango de respuestas de 0 -nunca a 3 -todo el tiempo-. La tabla 4 muestra estos datos.

\begin{tabular}{|c|c|c|c|c|c|}
\hline Emociones Positivas & media & Desv. T. & Emociones Negativas & media & Desv. T. \\
\hline SATISFACCIÓN & 1.47 &, 817 & ABURRIMIENTO & ,86 & ,826 \\
\hline ENTUSIASMO & 1.48 & 822 & FRUSTRACIÓN & ,79 & ,894 \\
\hline ORGULLO & 1.32 & 990 & ENFADO & 61 & 824 \\
\hline OPTIMISMO & 1.59 & 949 & FASTIDIO & 64 & 718 \\
\hline COMPETENCIA & 1.15 & 867 & CULPABILIDAD & 21 & 487 \\
\hline ALEGRÍA & 1.25 & ,822 & TRISTEZA & ,24 & ,471 \\
\hline ALIVIO & 1.68 & 937 & INSEGURIDAD & 95 & 907 \\
\hline SERENIDAD & 1.42 & 1,004 & ARREPENTIMIENTO & ,26 & ,515 \\
\hline EUFORIA & ,74 & 890 & SOLEDAD & ,43 & ,678 \\
\hline SEGURIDAD & 1.36 & 826 & ANGUSTIA-ANSIEDAD & ,71 & 899 \\
\hline TRANQUILIDAD & 1.33 & ,962 & DESESPERACIÓN & ,98 & ,973 \\
\hline PERSEVERANCIA & 1.41 & ,838 & ESTRÉS-CANSANCIO & .83 & 861 \\
\hline ACOMPAÑAMIENTO & ,93 & ,856 & APATÍA-DESGANA & ,72 & 812 \\
\hline CONFIANZA & 1.34 & 843 & DESCONFIANZA & 67 & ,906 \\
\hline ORIENTACIÓN & 1.78 & ,767 & VERGÜENZA & ,14 & ,441 \\
\hline ATRACCIÓN & 1.32 & ,880 & ASCO-REPULSION &, 10 & ,360 \\
\hline RECONOCIMIENTO & 1.17 & ,723 & DESORIENTADA/O & 1,12 & 957 \\
\hline AGRADECIMIENTO & 1.39 & ,910 & RABIA-IRA & ,25 & ,576 \\
\hline PODER & ,73 & ,848 & IMPOTENCIA & ,47 & ,681 \\
\hline ESTIMULO & 1,28 & ,988 & TENSIÓN-PREOCUPACIÓN & 1.17 & ,841 \\
\hline
\end{tabular}

Tabla 6. Resultados descriptivos de cada modalidad emocional (escala 0-3) 
Rebollo Catalán, Ma . A., García Pérez, R., Barragán Sánchez, R., Buzón García, O. y Vega Caro, L. (2008). Las emociones en el aprendizaje online. RELIEVE, v. 14, n. 1, p. 1-23.

http://www.uv.es/RELIEVE/v14n1/RELIEVEv14n1_2.htm

Las emociones positivas han estado más presentes en el aprendizaje online que las negativas en términos generales, observándose cómo prácticamente todas se sitúan en medias por encima de 1 , siendo la orientación $(1,78)$, alivio $(1,68)$ y optimismo $(1,59)$ las que obtienen medias más altas. Por su parte, las emociones negativas obtienen en su conjunto valores por debajo de 1 , siendo la tensión/preocupación y la desorientación con medias de 1,17 y 1,12 respectivamente las de mayor puntuación. El gráfico 5 ilustra esta tendencia.

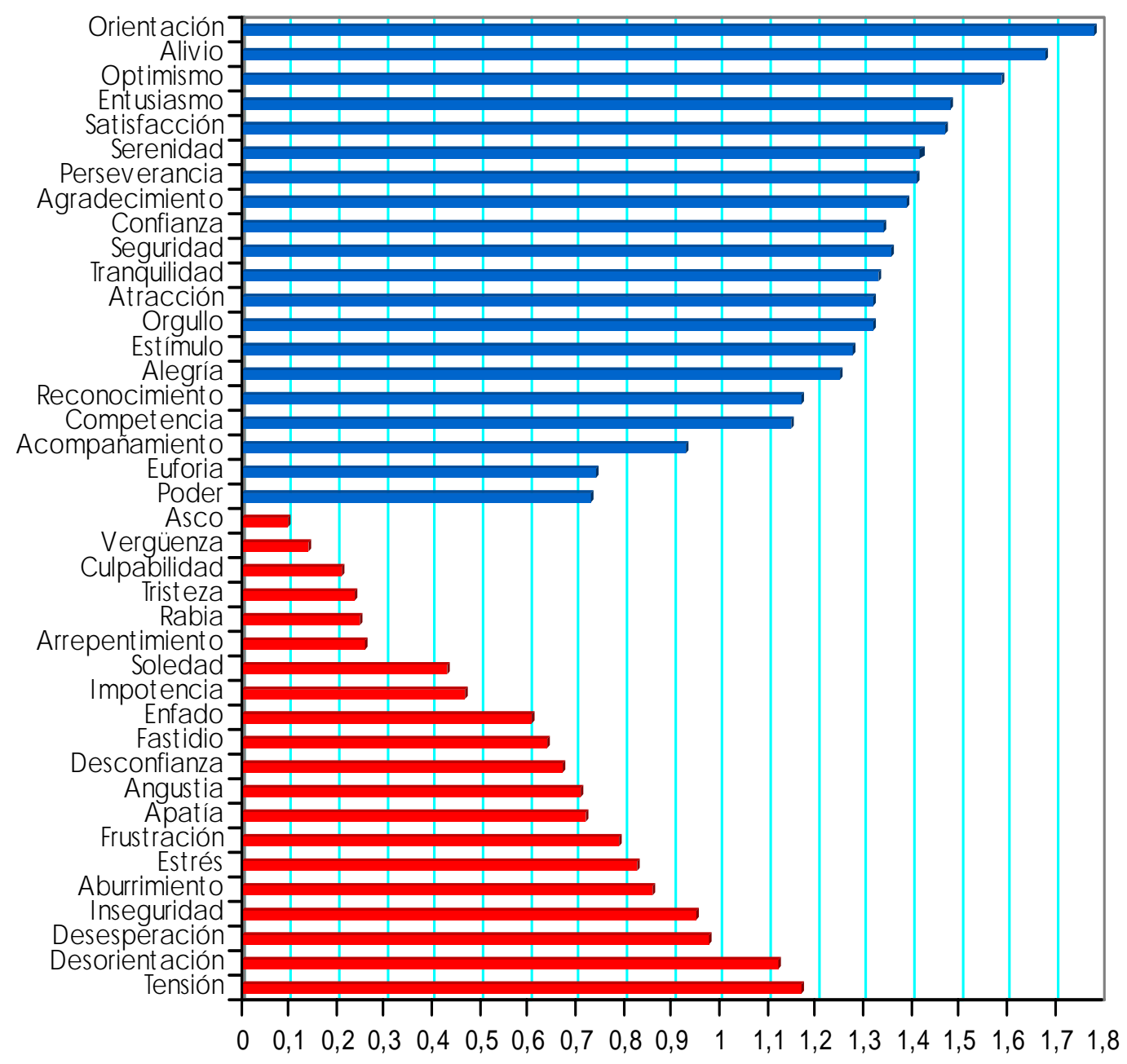

Gráfico 5. Catálogo de emociones del aprendizaje online

Este estudio también ha puesto al descubierto la malla de relaciones entre distintas emociones experimentadas durante el aprendizaje online. Los siguientes diagramas de flujos muestran los índices de correlación entre emociones. Estos revelan cómo casi todas las emociones positivas experimentadas correlacionan con el poder, es decir con procesos de empoderamiento. 
Rebollo Catalán, Ma . A., García Pérez, R., Barragán Sánchez, R., Buzón García, O. y Vega Caro, L. (2008). Las emociones en el aprendizaje online. RELIEVE, v. 14, n. 1, p. 1-23.

http://www.uv.es/RELIEVE/v14n1/RELIEVEv14n1_2.htm

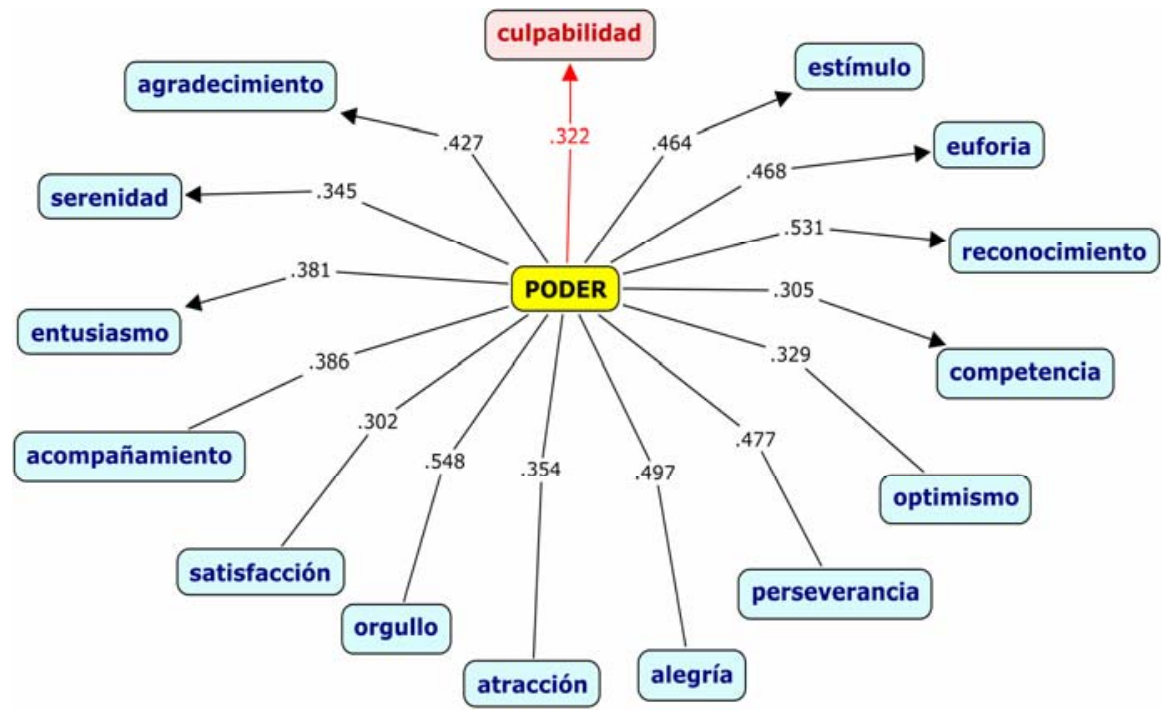

Gráfico 6. Emociones asociadas al poder

El poder correlaciona muy positivamente con todas las emociones positivas, pero más estrechamente con orgullo con una correlación de 0.548 , reconocimiento con 0.531 y alegría con 0.497. La única emoción negati- va que aparece asociada al poder es culpabilidad con un coeficiente de 0.322. No obstante, ésta correlaciona a su vez con otras emociones negativas, como presenta el diagrama de flujo siguiente:

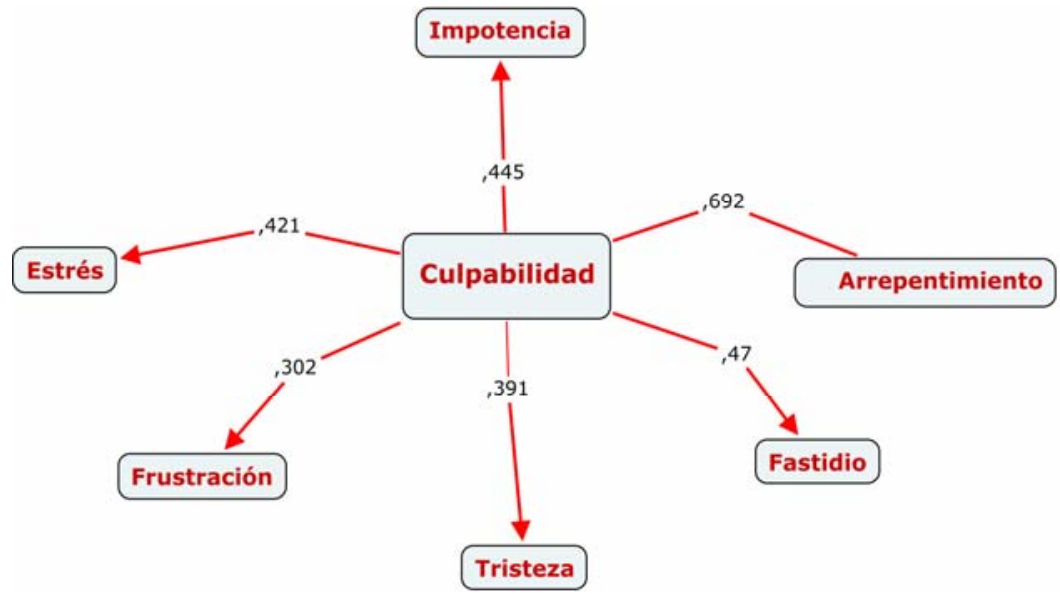

Gráfico 7. Emociones asociadas a la culpabilidad

La culpabilidad se asocia más estrechamente al arrepentimiento con un índice de correlación de .692. Esto parece apuntar a la asunción de una responsabilidad individual en el aprovechamiento de las TIC para el aprendizaje.

\subsection{Discursos emocionales en la comu- nicación online}

En este apartado presentamos los resultados derivados del análisis de los mensajes en foros de discusión y de la entrevista grupal.

En cuanto los mensajes de foros de discusión, se han registrado un total de 476 mensajes, en los cuales se ha observado: tipo de emoción, modo de interacción y agente. Las categorías empleadas para su análisis han sido: 
Rebollo Catalán, Ma . A., García Pérez, R., Barragán Sánchez, R., Buzón García, O. y Vega Caro, L. (2008). Las emociones en el aprendizaje online. RELIEVE, v. 14, n. 1, p. 1-23.

http://www.uv.es/RELIEVE/v14n1/RELIEVEv14n1_2.htm

\begin{tabular}{|c|c|c|}
\hline Variable & Categoría & Definición \\
\hline \multirow{3}{*}{ Interacción } & Consulta & $\begin{array}{l}\text { Intervención cuya finalidad es plantear y/o resolver una duda o consul- } \\
\text { ta, con frecuencia de carácter técnico. }\end{array}$ \\
\hline & Seguimiento & $\begin{array}{l}\text { Intervención cuyo objeto es pedir y/o ofrecer ayuda, consistente en } \\
\text { proporcionar información sobre las tareas de aprendizaje. }\end{array}$ \\
\hline & Valoración & $\begin{array}{l}\text { Intervención consistente en reflexiones y valoraciones sobre el proceso } \\
\text { de aprendizaje online. }\end{array}$ \\
\hline \multirow{10}{*}{ Emoción } & Orientación & Expresiones de guía, apoyo y sostén en relación con el aprendizaje \\
\hline & Gratitud & $\begin{array}{l}\text { Expresiones de agradecimiento y alivio por la colaboración, ayuda o } \\
\text { intervención de otra compañera. }\end{array}$ \\
\hline & Estímulo & $\begin{array}{l}\text { Expresiones de ilusión, ánimo, interés y motivación en relación con el } \\
\text { aprendizaje }\end{array}$ \\
\hline & Tranquilidad & $\begin{array}{l}\text { Expresiones de confianza, acompañamiento y seguridad en relación } \\
\text { con el aprendizaje. }\end{array}$ \\
\hline & Reconocimiento & $\begin{array}{l}\text { Expresiones de recompensa, premio y valoración de las acciones de } \\
\text { otra compañera. }\end{array}$ \\
\hline & Entusiasmo & $\begin{array}{l}\text { Expresiones de alegría y optimismo en relación con las tareas de } \\
\text { aprendizaje. }\end{array}$ \\
\hline & Satisfacción & $\begin{array}{l}\text { Expresiones de orgullo y competencia en relación con las tareas de } \\
\text { aprendizaje. }\end{array}$ \\
\hline & Preocupación & $\begin{array}{l}\text { Expresiones de tensión, inquietud, susto y miedo en relación con el } \\
\text { aprendizaje. }\end{array}$ \\
\hline & Confusión & $\begin{array}{l}\text { Expresiones de desconcierto, sorpresa, desorientación en relación con } \\
\text { el aprendizaje. }\end{array}$ \\
\hline & Inseguridad & $\begin{array}{l}\text { Expresiones que revelan duda, incertidumbre y desconfianza sobre el } \\
\text { aprendizaje. }\end{array}$ \\
\hline \multirow{2}{*}{ Agente } & Profesorado & Intervención realizada por el profesorado \\
\hline & Alumnado & Intervención realizada por el alumnado \\
\hline
\end{tabular}

Tabla 7. Descripción de variables y categorías del discurso emocional.

Los discursos en la comunicación online durante esta experiencia educativa muestran que el tipo de interacción más frecuente ha sido la consulta $(48,12 \%)$, seguida por seguimiento $(37,45 \%)$ y valoración $(14,02 \%)$ respectivamente. Paralelamente, los registros realizados en foros de discusión muestran una mayor variedad y presencia de emociones positivas. Otras emociones registradas se sitúan por debajo de un 2\% de aparición (alivio, euforia, enfado, impotencia, frustración, cansancio y arrepentimiento), por lo que no se han incluido en los gráficos debido a su escasa influencia en la comunicación online. Los gráficos siguientes muestran la presencia y distribución de tipos de emoción y formas de interacción. 
Rebollo Catalán, Ma . A., García Pérez, R., Barragán Sánchez, R., Buzón García, O. y Vega Caro, L. (2008). Las emociones en el aprendizaje online. RELIEVE, v. 14, n. 1, p. 1-23.

http://www.uv.es/RELIEVE/v14n1/RELIEVEv14n1_2.htm

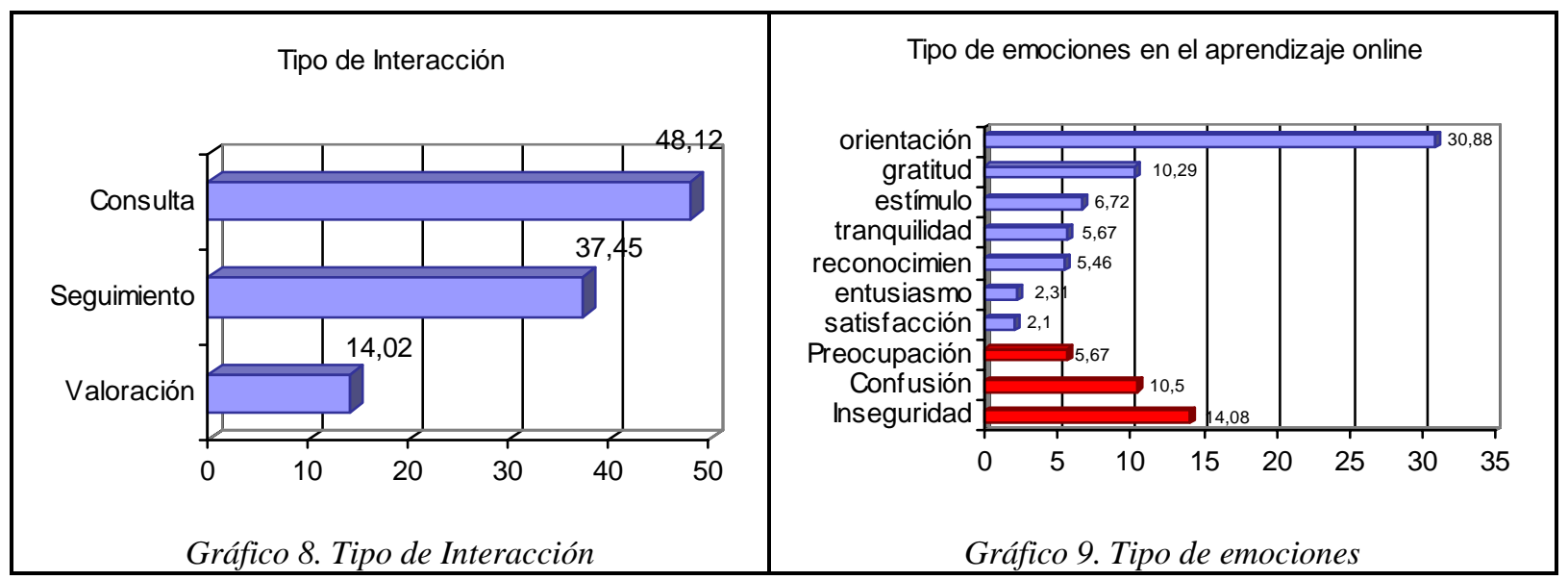

De forma complementaria y, a partir de las propuestas de Etchevers, hemos registrado diferentes códigos y reglas de escritura que refuerzan la expresión de emociones durante las interacciones online. Estos códigos aparecen en 141 mensajes de foro del total de
476 realizados, lo que supone un $30 \%$ de los discursos emitidos. El gráfico siguiente muestra la proporción de uso de estas formas de complementar la escritura para expresar emociones online.

Códigos y Reglas de

Expresión Emocional Online

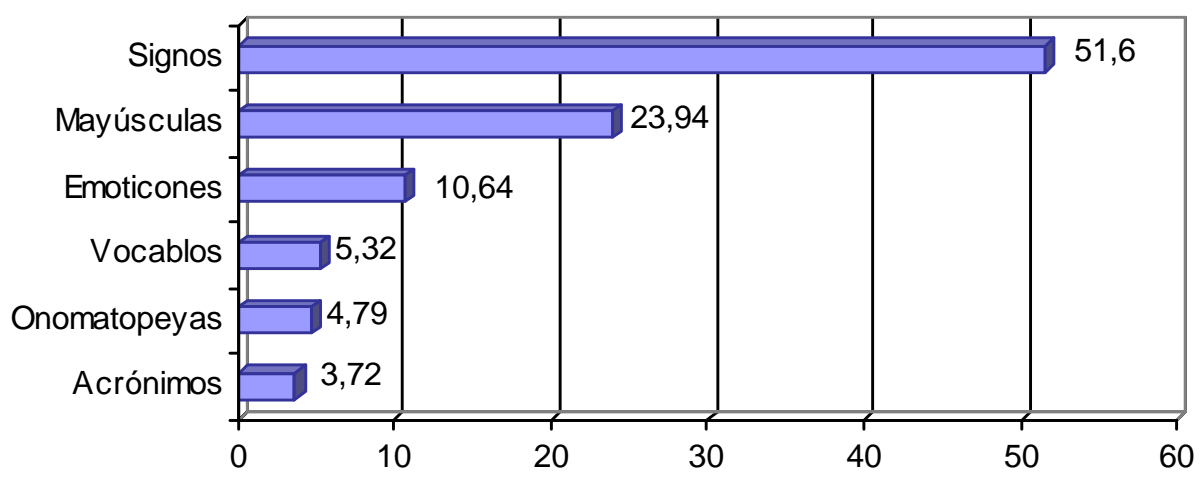

Gráfico 10. Códigos y Reglas de Expresión Emocional Online

Según estos datos, la repetición e intensificación de signos de puntuación han sido los más usados para realzar y expresar emociones online (gracias!!!!, ánimo!!!, donde se miran????) en un $51,6 \%$ de los discursos electrónicos, seguido del uso de mayúsculas presente en un $23,94 \%$ de los discursos
(POR FAVOR, GRACIAS, etc.) y de los emoticones $(\mathrm{J})$ con un 10,64\%.

El conocimiento de las emociones asociadas a cada modo de interacción online es otra de las aportaciones de este trabajo. La tabla siguiente muestra una descripción pormenorizada de las emociones asociadas a cada forma de interacción online. 
Rebollo Catalán, Ma . A., García Pérez, R., Barragán Sánchez, R., Buzón García, O. y Vega Caro, L. (2008). Las emociones en el aprendizaje online. RELIEVE, v. 14, n. 1, p. 1-23.

http://www.uv.es/RELIEVE/v14n1/RELIEVEv14n1_2.htm

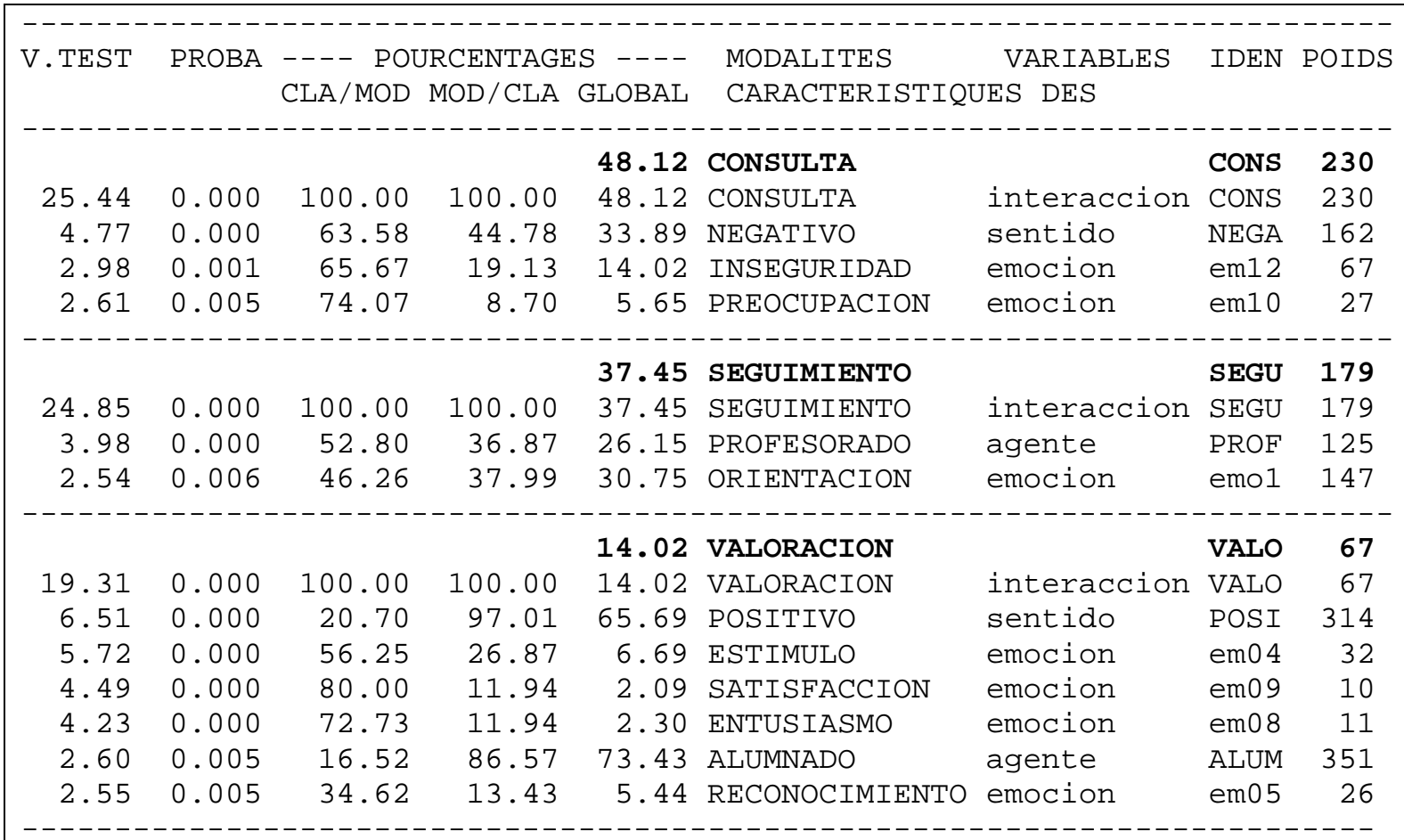

Tabla 8. Descripción de emociones asociadas a modos de interacción.

De este modo, las emociones asociadas a la consulta son inseguridad y preocupación, lo que se relaciona con el manejo y dominio de las tecnologías como recurso de aprendizaje. Algunos discursos son ilustrativos:

[E124] Hola!! donde se miran las prácticas subidas????? que quiero asegurarme que están todas enviadas. Graciaaaaaaaaaas.

[E238] Hola!!! quisiera saber si tenéis problemas con los cmaps?? Ya que hay algunos capítulos que son un poco largos. Además me gustaría saber cómo tengo que subirlos a la plataforma, uno a uno?? O todos en una carpeta comprimida???

Por su parte, la orientación es la emoción vinculada al seguimiento, siendo un tipo de interacción online protagonizada básicamente por el profesorado. Algunos mensajes de foros de discusión del profesorado resultan reveladores:
[E220] Hola Elisa, Es una práctica magníficamente bien resuelta en cuanto a lenguaje y contenido, es decir, que mi valoración es muy positiva. De todas formas, te he incluido algunas mejoras en algunas preguntas, porque creo que hubo un error en la interpretación de lo que había que hacer. Enhorabuena y continua así!!

[E252] Por favor, antes de plantear dudas $y$ cuestiones que generan inquietud a los demás compañeros y compañeras, leeos BIEN las instrucciones de cada práctica... Procurad que vuestras intervenciones en el foro sean útiles y constructivas. Mucho ánimo y no despistéis de lo fundamental. La práctica que os queda por entregar es la del experimento.

Por último, la comunicación orientada a la valoración y reflexión sobre el proceso de aprendizaje online se encuentra asociada a una variedad de emociones positivas (estímulo, satisfacción, entusiasmo y reconocimiento) experimentadas por el alumnado. 
Mostramos a continuación algunos discursos registrados en esta línea:

[E175] Me resulta asombroso cómo se interiorizan todos los conceptos al realizar un mapa conceptual, siempre he sacado conceptos claros a la hora de preparar exámenes, pero a partir de ahora, aunque me exceda un poco en el tiempo, voy a habituarme a realizar más mapas conceptuales para organizar y preparar las materias!!

[E161] Se termina el curso y seguro que si hacéis un balance, tampoco ha sido para tanto ¿no?. Muchas veces nos agobiamos al hacer (tarde) las tareas y preparar (tarde) los exámenes, y creo que la solución es enfrentarse directamente a nuestros miedos, en vez de darle tantas vueltas a la cabeza, en fin, espero que todas las tareas que hayáis acometido tengan un buen fin y logréis los resultados esperados! Un saludo a todos!!

Los discursos y expresiones registradas en la entrevista grupal realizada a la finalización del proceso de aprendizaje online también revelan una variedad de emociones experimentadas en el aprendizaje online. Los datos registrados en la entrevista muestran expresiones emocionales de odio y miedo en referencia a experiencias educativas anteriores en relación con la ciencia y la tecnología. En contraste, entusiasmo, satisfacción y confianza son las emociones expresadas en relación con la experiencia de aprendizaje online del presente curso. No obstante, lo más significativo desde un punto de vista afectivo es el cambio que muestra el alumnado en su relación emocional con contenidos de ciencias. Los discursos registrados en las entrevistas muestran este cambio:

\begin{tabular}{|c|c|}
\hline NEGATIVAS & POSITIVAS \\
\hline $\begin{array}{l}\text { S1E40: La rama de la investigación la odiaba y con } \\
\text { esta asignatura me he motivado y me ha cambiado } \\
\text { a decir ¿por qué no? }\end{array}$ & $\begin{array}{l}\text { S1E32. Me ha cambiado en todos los sentidos, soy } \\
\text { repetidora y antes no utilizaba la tecnología (...) la } \\
\text { práctica es lo que nos ayuda, es una manera de } \\
\text { salir de la carrera con ganas y saber que puedes } \\
\text { llevar cosas a la práctica. }\end{array}$ \\
\hline $\begin{array}{l}\text { S4E44: Yo le tenía mucho miedo a las ciencias } \\
\text { porque venía de letras puras y a través de esta } \\
\text { asignatura te vas metiendo más en este tema, te } \\
\text { abre nuevos caminos }\end{array}$ & $\begin{array}{l}\text { S4E21: (...) lo que me ha ayudado mucho es a la } \\
\text { hora de andar con seguridad con las nuevas tecno- } \\
\text { logías, seguridad que antes no tenía. }\end{array}$ \\
\hline
\end{tabular}

Tabla 9. Expresiones emocionales del aprendizaje online

\section{DISCUSIÓN}

En este trabajo, hemos presentado algunos resultados obtenidos con un modelo pedagógico semi-presencial (blended-learning) que incluye estrategias de regulación emocional en su desarrollo, detectándose una mayor presencia y variedad de emociones positivas que de emociones negativas durante el aprendizaje online por parte del alumnado.

La fuerte presencia constatada de la orientación como emoción de apoyo y guía durante el proceso de aprendizaje concuerda con los resultados aportados por otros estudios en relación con el aprendizaje online (Barragán et al., 2007), dibujándose como una competencia emocional significativa en la formación del profesorado para el ejercicio de su función tutorial en entornos virtuales. También se muestran con una fuerte presencia el alivio y el optimismo durante el aprendizaje online, emociones muy destacables en experiencias de aprendizaje a través de plataformas virtuales, en las que se requiere la gestión del propio aprendizaje, el uso de recursos y herramientas 
tecnológicas, etc. En contraste, las emociones negativas más presentes en el aprendizaje online han sido preocupación-tensión y desorientación-confusión, ambas revelan la importancia de adquirir competencias emocionales para un aprendizaje autónomo, es decir, la capacidad de autorregulación emocional en entornos virtuales.

Por otra parte, el papel preponderante de ciertas emociones en el aprendizaje online como poder y sus relaciones con orgullo, satisfacción, etc., muestran la importancia de las emociones morales en el aprendizaje online. Estos resultados concuerdan con las tesis de Hargreaves (2003) sobre el poder como fundamento de las lógicas de inclusión y exclusión académica. Los resultados obtenidos en el estudio muestran la presencia de emociones morales asociadas al poder, mostrándose éste un elemento clave en el aprendizaje online durante esta experiencia educativa. Esto sugiere la necesidad de estudiar la eficacia de los modelos educativos para promover el empoderamiento personal y social en relación con las emociones, es decir, analizar su potencialidad para fomentar y aumentar la capacidad de los estudiantes de acceder y controlar los recursos culturales (materiales y simbólicos) para hacer frente a las exigencias de su propia vida con objeto de comprender y explicar el papel de las emociones en los procesos de aprendizaje online. Los datos procedentes de este estudio abren una línea de reflexión sobre el diseño de contenidos y recursos educativos online desde la perspectiva de su capacidad para facilitar el aprendizaje de los estudiantes y promover procesos de empoderamiento.

Por otro lado, los discursos emocionales en la comunicación online revelan tres funciones educativas básicas: consulta, seguimiento y valoración. La consulta aparece asociada empíricamente a emociones de inseguridad $\mathrm{y}$ preocupación. Estos datos se muestran coincidentes con los registrados en la escala de malestar emocional en este mismo estudio, aportando información adicional sobre su aparición en el aprendizaje online. Estas emociones aparecen asociadas a la resolución de dudas y problemas de carácter técnico o administrativo. El seguimiento se asocia a orientación y tranquilidad, siendo discursos especialmente protagonizados por el profesorado. No obstante, merecen especial atención los discursos electrónicos orientados a la valoración y reflexión sobre el proceso de aprendizaje, ya que son realizados por el alumnado y se asocian a emociones positivas de satisfacción, entusiasmo, estímulo y reconocimiento. $\mathrm{La}$ aparición de este tipo de discursos en la interacción educativa podría asociarse al desarrollo de competencias metacognitivas de aprendizaje autónomo y reflexivo, objetivos de la formación presentes en las directrices y orientaciones del Espacio Europeo de Educación Superior. En esta vertiente, las valoraciones realizadas por el alumnado sobre la relación emocional con la ciencia y la tecnología centradas en el entusiasmo, la satisfacción y la confianza son especialmente valorables en relación con el perfil del alumnado participante en la experiencia, constituido en un $47,4 \%$ por repetidores.

En este estudio hemos presentado una metodología para el estudio de las emociones en procesos de aprendizaje online, combinando técnicas cuantitativas y cualitativas. Además, se plantea desde una teoría constructivista y dialógica de las emociones compatibles con las concepciones actuales sobre el aprendizaje presentes en las orientaciones del Espacio Europeo de Educación Superior. Esta incipiente línea de investigación sobre la comprensión y fenomenología de las emociones en el aprendizaje online no se agota en estos primeros resultados. Otros desarrollos centrados sobre la secuencia y flujos de interacción educativa en la comunicación online así como el estudio de los procesos de regulación emocional en comunidades virtuales de aprendizaje constituyen retos futuros para la mejora de los procesos educativos en entornos virtuales.

Este trabajo implica un estudio preliminar de una prometedora línea de investigación en el campo de la educación sobre emociones, 
aprendizaje y entornos educativos virtuales. La tasa de abandono y fracaso en los modelos de teleformación y e-learning plantea la necesidad de incorporar el estudio de las emociones en relación con el aprendizaje online (cómo surgen, qué papel juegan, de qué forma contribuyen al desarrollo de competencias, etc.).

\section{REFERENCIAS BIBLIOGRÁFI- CAS}

Aliaga, Francisco y Bartolomé, Antonio (2006). El impacto de las nuevas tecnologías en educación. En Tomás Escudero y Ana Delia Correa (Coords.). Investigación en innovación educativa (pp. 55-88). Madrid: La Muralla.

Aires, Luisa; Teixeira, António; Azevedo, José; Gaspar, María Ivone y Silva, Silvia (2006). Alteridad y emociones en las comunidades virtuales de aprendizaje. Revista electrónica Teoría de la Educación, 7 (2), 74-91.Consultado el 10 de enero de 2007 en http://www.usal.es/ teoriaeducacion/rev_nu mero_07_02/n7_02_luisa_aires.pdf

Ardizzone, Paolo y Rivoltella, Pier C. (2004). Didáctica para e-learning. Métodos e instrumentos para la innovación de la enseñanza universitaria. Málaga: Aljibe.

Barragán, Raquel; Buzón, Olga y García Pérez, Rafael (2007). Diagnóstico y evaluación de aprendizajes universitarios con eportafolios: regulación de aprendizajes Blended-Learning y nuevos roles del alumnado. En Felipa Etxeberría, Lander Sarasola, José Francisco Lukas, Juan Etxeberría y Aitor Martxueta (Coords.). Actas del XIII Congreso Nacional de Modelos de Investigación Educativa, AIDIPE: San Sebastián, 958-964.

Bautista, Guillermo; Borges, Federico y Forés, Anna (2006). Didáctica universitaria en entornos virtuales de enseñanza-aprendizaje. Madrid: Narcea.

Bostock, Stephen J. y Lizhi, Wu (2005). Gender in student online discussions. Innovations in Education and Teaching International, 43 (1), 73-85.
Cabrera, Lidia; Bethencourt, José Tomas; González, Miriam y Álvarez, Pedro (2006). Un estudio transversal retrospectivo sobre prolongación y abandono de estudios universitarios. Revista Electrónica de Investigación y Evaluación Educativa, 12(1), 129-149.

Colás, Pilar y De Pablos, Juan (2005). La Universidad en la Unión Europea: El espacio Europeo de Educación Superior y su impacto en la docencia. Málaga: Aljibe.

De Miguel, Mario (Coord.)(2006). Metodologías de enseñanza y aprendizaje para el desarrollo de competencias. Madrid: Alianza.

De Pablos, Juan; Rebollo, $\mathrm{M}^{\mathrm{a}}$ Angeles y Lebres, Luisa (1999). Para un estudio de las aportaciones de Mijaíl Bajtín a la Teoría Sociocultural. Una aproximación Educativa. Revista de Educación, 320, 223-253.

Edwards, Derek (1999). Emotion Discourse. Culture \& Psychology, 5(3), 271-291.

Efklides, Anastasia (2006). Metacognition and affect: What can metacognitive experiences tell us about the learning process?? Educational Research Review, 1, 3-14

Etchevers, Nicole (2005). ¿Dónde estan las emociones en el ciberspacio? Análisis de la situación actual. Revista TEXTOS de la Cibersociedad, 5. Consultado el 24 de junio de 2006 en http://www.cibersociedad.net/textos/articulo. php?=71

Etchevers, Nicole (2006). Los nuevos códigos de la comunicación emocional utilizados en Internet. Revista Electrónica de Teoría de la Educación, 7(2), 92-106. Consultado el 10 de enero de 2007 en http://www.usal.es/ teoriaeducacion/rev_nu mero_07_02/n7_02_nicole_etchevers.pdf

García Pérez, Rafael (2001). La resolución de problemas. En M.A. Rebollo (Coord.). Discurso y Educación (123-151). Sevilla: Mergablum.

García Pérez, Rafael (2002). Diagnóstico de la dimensión emocional en la resolución de problemas escolares. II Congreso Europeo de Tecnologías de la Información en la Educación y la Ciudadanía: una Visión Crítica. Barcelona. 26-28 Junio (paper). 
Garrison, D.R. y Anderson, Terry (2005). El e-learning en el siglo XXI. Investigación y Práctica. Barcelona: Octaedro.

Gover, Mark (1996). Educating the emotions: implications of a relational view of knowing for learning and development. Annual Meeting of AERA, Chicago (paper). Consultado el 24 de septiembre de 2002 en http://www.msu.edu/user/govermar/emotion. $\underline{\mathrm{htm}}$

Gover, Mark R. y Gavelek, James (1997). Educating the emotions: Implications of a relational view of knowing for learning and development. Annual Meeting of AERA, Chicago (paper). Consultado el 24 de septiembre de 2002 en http://www.msu.edu/user/govermar/emotion. $\underline{\mathrm{htm}}$

Hargreaves, Andy (2003). Política emocional en el fracaso y éxito escolar. En A. Marchesi y C. Hernández (Comp.), El fracaso escolar: una perspectiva internacional (pp. 229-254). Madrid: Alianza.

Hernández, Fuensanta; Rosario, Pedro; Cuesta, José David; Martínez, Pilar y Ruiz, Encarna (2006). Promoción del aprendizaje estratégico y competencias de aprendizaje en estudiantes de primero de Universidad: evaluación de una intervención. Revista de Investigación Educativa, 24(2), 615-632.

Hong, Guy-Young (2004). Emotions in culturally-constituted relational worlds. Culture \& Psychology, 10(1), 53-63.

Marchesi, Alvaro y Hernández, Carlos (Coords.) (2003). El fracaso escolar: una perspectiva internacional. Madrid: Alianza.

Pekrun, Reinhard (2005). Progress and open problems in educational emotion research. Learning and Instruction, 15, 497-506.

Rebollo, Ma Ángeles (2006) Emociones, género e identidad: la educación sentimental. En $\mathrm{M}^{\mathrm{a}}$ Ángeles Rebollo (Coord.). Género $e$ interculturalidad: educar para la igualdad (pp. 217-244) Madrid: La Muralla.

Rebollo, M ${ }^{\mathrm{a}}$ Ángeles; García, Rafael, Vega, Luisa; Mesones, Ana; Ruiz, Estrella; Cárcamo, Sissi C. y Vázquez, Alicia (en prensa).
Género, Ciencia y TIC: formación científica online con perspectiva de género. Revista de Enseñanza Universitaria, 29.

Rebollo, $\mathrm{M}^{\mathrm{a}}$ Ángeles; Hornillo, Inmaculada y García, Rafael (2006). Estudio educativo de las emociones: una perspectiva sociocultural. Revista Electrónica de Teoría de la Educación, 7(2), 28-44. Consultado el 10 de enero de 2007 en

http://www.usal.es/ teoriaeducacion/rev_nu mero_07_02/n7_02_mangeles_rebollo.pdf

Rebollo, M ${ }^{\mathrm{a}}$ Angeles; García, Rafael; Barragán, Raquel y Buzón, Olga (2007). Las emociones desde un prisma sociocultural: Aprendizaje online y emociones. En Luisa Aires, José Azevedo, Ivone Gaspar y António Teixeira (Coords.). Comunidades Virtuais de aprendizagem e identidades no ensino superior: o projecto @aprende.com (pp.39-49). Porto: Universidade Aberta.

Seymour, Jennifer R. y Osana, Helena P. (2003). Reciprocal teaching procedures and principles: two teachers' developing understanding. Teaching and Teacher Education. 19, 325-344.

Wertsch, James V. (1993). Voces de la mente. Un Enfoque Sociocultural para el estudio de la acción mediada. Madrid: Visor.

Zembylas, Michalinos y Kaloyirou, Chrystalla (2007). Emociones y violencia contra las mujeres y otros grupos. Implicaciones pedagógicas. Revista de Educación, 342, 37-59.

\section{NOTAS}

1. Este artículo presenta resultados del proyecto de innovación: Contenidos formativos online con perspectiva de género, financiado por el Vicerrectorado de Docencia de la Universidad de Sevilla para su realización durante el curso 2006/07. Han participado en su realización: Estrella Ruiz Pinto y Ana Mesones Calvillo. Agradecemos al Vicerrectorado de Docencia y al Instituto de Ciencias de la Educación de la Universidad de Sevilla el apoyo recibido. 


\section{$\underline{\text { ABOUT THE AUTHORS / SOBRE LOS AUTORES }}$}

Rebollo Catalán, $\mathbf{M}^{\mathrm{a}}$ Ángeles (rebollo@us.es) Doctora en Pedagogía y Profesora Titular de Métodos de Investigación y Diagnóstico en Educación de la universidad de Sevilla. Su línea de investigación principal es Género, Tecnología y Educación. Actualmente dirige el proyecto de excelencia “Teón XXI: creación de recursos digitales para la coeducación” (P06-HUM-01408), financiado por la Consejería de Innovación Ciencia y Empresa de la Junta de Andalucía. Sus últimas publicaciones se vinculan al género y las emociones desde una perspectiva educativa. Es la autora de referencia para este artículo. Su dirección es C/ Camilo José Cela s/n. Facultad de Educación. Universidad de Sevilla. 41018 - Sevilla (España). Buscar otros artículos de este autor en Scholar Google

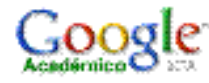

García Pérez, Rafael (rafaelgarcia@us.es). Doctor en Pedagogía. Profesor Titular de Métodos de Investigación y Diagnóstico en Educación de la universidad de Sevilla. Su línea de investigación principal es E-learning y las TIC en Educación. En esta línea sus últimos trabajos se han desarrollado en el nivel universitario, vinculados a sendos proyectos de innovación educativa financiados por la Universidad de Sevilla y la Unidad para la Calidad de las Universidades Andaluzas respectivamente, por los cuales ha recibido un premio a su calidad y excelencia. Su dirección es C/ Camilo José Cela s/n. Facultad de Educación. Universidad de Sevilla. 41018 - Sevilla (España).

Barragán Sánchez, Raquel (rbarragan@us.es). Licenciada en Pedagogía. Actualmente es Asistente Honoraria del Dpto. MIDE. Profesora Asociada del Dpto. MIDE durante el año académico 2006/2007. En la actualidad trabaja como coordinadora de proyectos de investigación en el Instituto de Formación y Estudios Sociales de Andalucía y está realizando la tesis doctoral en la línea de investigación E-learning y las TIC en Educación. Forma Parte de la Red Nacional de I+D sobre e-portafolio, financiado por el MEC. Ha participado en proyectos de ámbito nacional sobre el EEES y la aplicación de las TIC en la enseñanza universitaria. Su dirección es C/ Camilo José Cela s/n. Facultad de Educación. Universidad de Sevilla. 41018 - Sevilla (España).

Buzón García, Olga (olgbuzgar@alum.us.es). Licenciada en Pedagogía. Actualmente es Asistente Honoraria del Dpto. MIDE. En la actualidad trabaja como coordinadora de proyectos de investigación en el Instituto de Formación y Estudios Sociales de Andalucía y está realizando la tesis doctoral en la línea de investigación E-learning y las TIC en Educación. Forma Parte de la Red Nacional de I+D sobre e-portafolio, financiado por el MEC. Ha participado en proyectos de ámbito nacional sobre el EEES y la aplicación de las TIC en la enseñanza universitaria.Su dirección es C/ Camilo José Cela s/n. Facultad de Educación. Universidad de Sevilla. 41018 - Sevilla (España).

Vega Caro, Luisa (luiveg@us.es). Licenciada en Pedagogía. Actualmente es Becaria de FPI del Dpto. MIDE. Ha participado en sendos proyectos de innovación en la docencia universitaria sobre aprendizaje online y portafolios electrónicos financiados por el Vicerrectorado de Docencia de la Universidad de Sevilla. Su dirección es C/ Camilo José Cela s/n. Facultad de Educación. Universidad de Sevilla. 41018 - Sevilla (España). 
Rebollo Catalán, Ma. A., García Pérez, R., Barragán Sánchez, R., Buzón García, O. y Vega Caro, L. (2008). Las emociones en el aprendizaje online. RELIEVE, v. 14, n. 1, p. 1-23.

http://www.uv.es/RELIEVE/v14n1/RELIEVEv14n1_2.htm

\title{
ARTICLE RECORD / FICHA DEL ARTÍCULO
}

\begin{tabular}{|c|c|}
\hline $\begin{array}{l}\text { Reference / } \\
\text { Referencia }\end{array}$ & $\begin{array}{l}\text { Rebollo Catalán, Ma Ángeles, García Pérez, Rafael, Barragán Sánchez, Raquel, Buzón García, Olga, Ve- } \\
\text { ga Caro, Luisa (2008). Las emociones en el aprendizaje online. } R E L I E V E, \text { v. 14, n. 1. } \\
\text { http://www.uv.es/RELIEVE/v14n1/RELIEVEv14n1_2.htm. Consultado en (poner fecha). }\end{array}$ \\
\hline $\begin{array}{l}\text { Title / } \\
\text { Título }\end{array}$ & Las emociones en el aprendizaje online. [Emotions in e-learning] \\
\hline $\begin{array}{l}\text { Authors / } \\
\text { Autores }\end{array}$ & $\begin{array}{l}\text { Rebollo Catalán, Ma Ángeles; García Pérez, Rafael; Barragán Sánchez, Raquel; Buzón García, Olga; Ve- } \\
\text { ga Caro, Luisa }\end{array}$ \\
\hline $\begin{array}{l}\text { Review / } \\
\text { Revista }\end{array}$ & Revista ELectrónica de Investigación y EValuación Educativa (RELIEVE), v. 14, n. 1 \\
\hline ISSN & $1134-4032$ \\
\hline $\begin{array}{l}\text { Publication } \\
\text { date / } \\
\text { Fecha de } \\
\text { publicación }\end{array}$ & $\begin{array}{l}\text { 2008 (Reception Date: } 2008 \text { January 29; Approval Date: } 2008 \text { May 28; Publication Date: } 2008 \text { May } \\
\text { 29) }\end{array}$ \\
\hline $\begin{array}{l}\text { Abstract / } \\
\text { Resumen }\end{array}$ & $\begin{array}{l}\text { This paper presents the results of an educational innovation in Higher Education, whose aim is to design } \\
\text { and test a pedagogical model for e-learning. This paper has the main aim to identify and evaluate emo- } \\
\text { tional factors related to e-learning by means of a survey research. The results show emotional well-being } \\
\text { scores higher than wrong-being, identifying a range of emotions, which are related to different emotional } \\
\text { states in e-learning. In addition, we present features of teachers' and students' virtual discourses in fo- } \\
\text { rums of discussion starting from types of educational interaction and kind of emotions related to certain } \\
\text { settings of learning activity. } \\
\text { Este artículo presenta parte de los resultados de una innovación educativa en el nivel universitario, cuyo } \\
\text { propósito es elaborar y experimentar un modelo pedagógico para el aprendizaje online. Con este estudio } \\
\text { pretendemos reconocer y valorar las emociones implicadas en el aprendizaje online mediante un método } \\
\text { descriptivo de tipo encuesta. Los resultados indican mayor nivel de bienestar emocional que de malestar, } \\
\text { identificándose las emociones asociadas a estos estados emocionales presentes en el aprendizaje online. } \\
\text { También presentamos las características de los discursos virtuales del profesorado y del alumnado en } \\
\text { función de tipos de interacción y emociones asociadas a determinados contextos de actividad. }\end{array}$ \\
\hline $\begin{array}{l}\text { Keywords / } \\
\text { Descripto- } \\
\text { res }\end{array}$ & $\begin{array}{l}\text { E-learning; higher education; emotions; emotional regulation; pedagogy of emotions. } \\
\text { Aprendizaje online; educación superior; emociones; regulación emocional; pedagogía de las emociones }\end{array}$ \\
\hline $\begin{array}{l}\text { Institution / } \\
\text { Institución }\end{array}$ & Universidad de Sevilla (España). \\
\hline $\begin{array}{l}\text { Publication } \\
\text { site / } \\
\text { Dirección }\end{array}$ & http://www.uv.es/RELIEVE \\
\hline $\begin{array}{l}\text { Language / } \\
\text { Idioma }\end{array}$ & Spanish (Title, abstract and keywords in English ) \\
\hline
\end{tabular}

\section{Revista ELectrónica de Investigación y $\mathbf{E V}$ aluación Educativa (RELIEVE)}

[ ISSN: 1134-4032 ]

\begin{abstract}
(C) Copyright, RELIEVE. Reproduction and distribution of this articles it is authorized if the content is no modified and their origin is indicated (RELIEVE Journal, volume, number and electronic address of the document).

(C) Copyright, RELIEVE. Se autoriza la reproducción y distribución de este artículo siempre que no se modifique el contenido y se indique su origen (RELIEVE, volumen, número y dirección electrónica del documento).
\end{abstract}

